\title{
Financial Stability, Personal Financial Need, Financial Target, External Pressure dan Financial Statement Fraud
}

\author{
Sukma Indah Purnama ${ }^{1}$ \\ Ida Bagus Putra Astika ${ }^{2}$ \\ 1,2Fakultas Ekonomi dan Bisnis Universitas Udayana, Indonesia \\ *Correspondences : sukmaindahpurnama@gmail.com
}

\begin{abstract}
ABSTRAK
Tujuan penelitian ini adalah untuk menguji secara empiris pengaruh faktor tekanan (pressure) yang terdiri dari financial stability, personal financial need, financial target dan external pressure pada financial statement fraud. Sampel penelitian sebanyak 147 perusahaan manufaktur yang terdaftar di Bursa Efek Indonesia pada tahun 2015-2019. Data diperoleh dari data sekunder annual report perusahaan manufaktur (2015-2019) yang selanjutnya dianalisis dengan regresi linier berganda. Hasil penelitian menunjukan adanya pengaruh dari variabel financial stability dan financial target memiliki pada financial satement fraud, namun sebaliknya tidak ditemukan pengaruh antara variabel personal financial need dan external pressure pada financial statement fraud.
\end{abstract}

Kata Kunci: Financial Stability; Personal Financial Need; Financial Target; External Pressure; Financial Statement Fraud.

\section{Financial Stability, Personal Financial Need, Financial Target, External Pressure and Financial Statement Fraud}$$
\text { ABSTRACT }
$$

The purpose of this study was to empirically examine the influence of pressure factors consisting of financial stability, personal financial need, financial target and external pressure on financial statement fraud. The research sample was 147 manufacturing companies listed on the Indonesia Stock Exchange in 2015-2019. The data was obtained from secondary data from the annual report of manufacturing companies (2015-2019) which was then analyzed by multiple linear regression. The results showed that there was an effect of financial stability and financial target variables on financial statement fraud, but on the contrary, there was no influence between personal financial need and external pressure variables on financial statement fraud.
\end{abstract}

Keywords: $\quad$ Financial Stability; Personal Financial Need; Financial Target; External Pressure; Financial Statement Fraud.

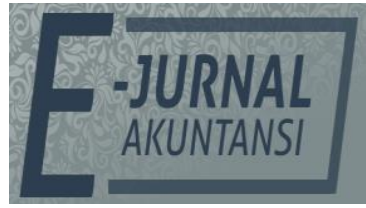

e-ISSN 2302-8556

Vol. 32 No. 1

Denpasar, Januari 2021

Hal. 209-221

DOI:

10.24843/EJA.2022.v32.i01.p15

PENGUTIPAN:

Purnama, S. I. \& Astika, I. B. P. (2022). Financial Stability, Personal Financial Need, Financial Target, External Pressure dan Financial Statement Fraud. E-Jurnal Akuntansi, 32(1), 209-221

RIWAYAT ARTIKEL: Artikel Masuk: 13 Juli 2021

Artikel Diterima: 24 September 2021

Artikel dapat diakses : https://ojs.unud.ac.id/index.php/Akuntansi/index 


\section{PENDAHULUAN}

Fraud atau kecurangan merupakan tindakan curang yang dilakukan sedemikian rupa, sehingga menguntungkan diri sendiri, kelompok, atau pihak lain yang sengaja dilakukan sehingga dapat menimbulkan kerugian yang tanpa disadari oleh pihak yang dirugikan. Kecurangan hingga saat ini merupakan salah satu hal yang fenomenal, baik di negara berkembang maupun negara maju. Kecurangan merupakan penyimpangan dan perbuatan hukum yang dilakukan secara sengaja, untuk keuntungan pribadi atau kelompok yang secara langsung maupun tidak langsung merugikan pihak lain.

Fenomena sosial mengenai fraud masih banyak terjadi, salah satunya kasus ernon yang melakukan manipulasi pada laporan keuangannya dengan mencatatkan laba padahal perusahaan mengalami kerugian. Manipulasi ini dilakukan agar investor tetap tertarik untuk melakukan investasi yang besar ke perusahaan ernon. Kasus ini tidak terlepas dari agency theory yang menjelaskan adanya conflict of interest dalam hubungan pemegang saham (principal) dan manajer sebagai agent, dimana conflict of interest menimbulkan tekanan (pressure) bagi manajer yang dapat memicu manajer melakukan financial statement fraud. Ilustrasi faktor kecurangan dijelaskan dalam ISA no.240 dan SAS no.99 yang menyebutkan bahwa salah satu kondisi yang selalu hadir saat terjadi kecurangan laporan keuangan adalah tekanan (pressure) terdiri dari financial stability, personal financial need, financial target dan external pressure.

Penelitian ini mengangkat fenomena pengaruh faktor tekanan (pressure) yang terdiri dari financial stability, personal financial need, financial target dan external pressure terhadap financial statement fraud. Hasil penelitian ini diharapkan dapat memberikan informasi kepada investor yang akan melakukan investasi agar dapat mengetahui faktor apa saja yang dapat menimbulkan terjadinya kecurangan laporan keuangan sehingga mengurangi potensi investor mengalami kerugian dalam berinvestasi.

Agency theory merupakan (grand theory) yang digunakan dalam penelitian ini, teori ini menjelaskan hubungan pemegang saham (principal) dengan manajer (agent), diasumsikan bahwa antara pemegang saham dan manajer terinovasi untuk memperbesar keuntungan bagi diri sendiri. Pemegang saham sebagai principal menginginkan peningkatan kinerja keuangan perusahaan berupa tingkat pengembalian yang tinggi atas investasi mereka. Sedangkan manajer sebagai agent menginginkan apresiasi berupa kompensasi keuangan dari pemegang saham atas kinerja yang telah manajer lakukan. Adanya perbedaan kepentingan antara principal dan agent menyebabkan conflict of interest diantara kedua pihak. Conflict of interest dapat menimbulkan tekanan bagi manajer sebagai agent untuk menemukan cara agar kinerja perusahaan selalu meningkat dengan harapan bahwa dengan meningkatkan kinerja perusahaan maka manajer akan mendapatkan apresiasi dari principal.

Financial stability merupakan salah satu faktor tekanan yang dapat memicu manajer untuk melakukan financial statement fraud ketika stabilitas keuangan 
(terancam oleh keadaan ekonomi, industri, dan situasi entitas yang beroperasi (Skousen, et al., 2011). Sesuai dengan hubungan pemegang sahan (principal) dan manajer (agent) pada agency theory, manajer merupakan pihak yang dikontrak oleh pemegang saham untuk bekerja demi kepentingan pemegang saham. Manajer akan memberikan kinerja yang optimal untuk menjaga kestabilan keuangan perusahaan demi kepentingan pemegang saham, namun dalam kenyataannya manajer banyak mengalami permasalahan untuk menjaga stabilitas keuangan perusahaan (Ijudien, 2018).

Penelitian yang dilakukan oleh Skousen, et al., (2011) dalam Iqbal \& Murtanto, (2016) menunjukkan bahwa ACHANGE berpengaruh positif terhadap financial statement fraud. Penelitian tersebut sejalan dengan Annisya, et al., (2016), Siddiq, et al., (2017), Bawekes, et al., (2018), Siddiq, et al., (2017), Saputra \& Kusumaningrum, (2017), Alfina \& Amrizal, (2020) yang menunjukkan bahwa financial stability yang diproksikan dengan ACHANGE terbukti berpengaruh terhadap financial statement fraud.

Manajer akan mendapatkan tekanan dalam menjaga stabilitas keuangan perusahaan apabila manajer tidak mengelola asset perusahaan dengan baik sehingga memperlihatkan kondisi keuangan perusahaan tidak stabil. Manajer dapat mengambil risiko melakukan manipulasi terhadap asset perusahaan agar kondisi keuangan perusahaan terlihat stabil, dalam hal ini asset sangat berperan untuk menampilkan keadaan yang stabil. Financial stability diproksikan dengan rasio pertumbuhan perubahan asset pertahun (ACHANGE). Berdasarkan penjelasan tersebut dapat disusun hipotesis yang pertama yaitu, semakin tinggi rasio perubahan total aset suatu perusahaan maka semakin tinggi juga tingkat risiko kecurangan pada laporan keuangannya.

$\mathrm{H}_{1}$ : Financial stability berpengaruh positif pada financial statement fraud.

Personal financial need merupakan suatu kondisi dimana keuangan perusahaan ikut dipengaruhi oleh kondisi keuangan pribadi eksekutif perusahaan (Setiawati \& Baningrum, 2018, Utomo, 2018). Berdasarkan agency theory apabila peran pemegang saham (principal) dan manajer (agent) dipegang oleh satu orang dalam satu perusahaan maka dapat menimbulkan terjadinya financial statement fraud karena antara peran principal dan agent memiliki perbedaan kepentingan.

Penelitian yang dilakukan Skousen, et al., (2011), Utomo, (2018) menyatakan bahwa variabel personal financial need yang diproksikan dengan presentase kepemilikian manajerial berpengaruh positif terhadap kecurangan laporan keuangan, karena tingginya rata-rata kepemilikan saham manajerial yang dapat mengidentifikasikan bahwa pada perusahaan telah terjadi pemisahan yang tidak jelas antara pemegang saham sebagai pemilik yang mengontrol jalannya perusahaan dan manajer sebagai pengelola perusahaan.

Adanya kepemilikan saham dimiliki oleh orang dalam perusahaan, dapat mempengaruhi kondisi keuangan perusahaan karena yang bersangkutan merasa mempunyai hak klaim atas penghasilan dan aktiva perusahaan (Yesiariani \& Rahayu, 2016). Manajer yang mempunyai kepemilikan saham perusahaan bukan hanya berperan sebagai pengelola perusahaan, tetapi juga berperan sebagai 
pengawas kegiatan operasi perusahaan. Kondisi ini dapat menimbulkan tekanan terhadap kepentingan pribadi bagi manajer yang dapat memicu terjadinya tindak kecurangan.

Personal financial need diproksikan dengan rasio antara jumlah saham yang dimiliki pihak manajerial (manajer dan direksi) terhadap total saham yang beredar pada perusahaan. Berdasarkan penjelasan tersebut, maka dirumuskan hipotesis kedua yaitu semakin tinggi kepemilikan manajerial oleh manajer, direksi maupun komisaris perusahaan maka semakin tinggi juga potensi terjadinya manipulasi laporan keuangan.

$\mathrm{H}_{2}$ : Personal financial need berpengaruh positif pada financial statement fraud.

Financial target adalah target keuangan yang diberikan oleh pemegang saham dan dan harus dicapai manajer dalam satu periode. Berkaitan dengan agency theory dalam hal target keuangan pemegang saham dan manajer memiliki kepentingan yang berbeda, pemegang saham hanya ingin target keuangan yang sudah ditentukan dapat dicapai oleh manajer bagaimanapun caranya. Manajer menginginkan bonus atas kinerjanya telah mencapai target keuangan yang ditentukan. Perbedaan kepentingan ini dapat menyebabkan potensi terjadinya financial statement fraud.

Penelitian yang dilakukan oleh Haryono, (2017), Wahyuni \& Budiwitjaksono, (2017), Zaki, (2017), Iqbal \& Murtanto, (2016), Prasmaulida, (2016), Nurrizkiana, (2015), Annisya, et al., (2016) membuktikan bahwa financial target tidak berpengaruh terhadap financial statement fraud. Penelitian tersebut sejalan dengan penelitian Mardianto \& Tiono, (2019) membuktikan bahwa tingkat nilai ROA yang rendah atau tinggi tidak akan mempengaruhi perusahaan untuk melakukan kecurangan laporan keuangan.

Return on Asset (ROA) dijadikan proksi untuk variabel financial target karena ROA sering digunakan untuk mengukur kinerja manajer, selain itu juga digunakan untuk melihat rasio profitabilitas sebagai pertimbangan pengambilan keputusan berinvestasi. Kenaikan ROA yang tinggi dapat menjadi indikasi perusahaan melakukan financial statement fraud, namun kenaikan rasio profitabilitas perusahaan juga dapat diakibatkan peningkatan mutu operasional perusahaan, apabila pemegang saham memberikan target ROA yang tinggi, manajer bisa saja mengatasinya dengan meningkatkan mutu operasional perusahaan sehingga target ROA yang tinggi tidak dapat menjadi faktor manajemen untuk melakukan kecurangan laporan keuangan. Berdasarkan penjelasan tersebut maka dapat disusun hipotesis ketiga yaitu, semakin tinggi target nilai ROA perusahaan maka semakin rendah kemungkinan terjadinya financial statement fraud.

$\mathrm{H}_{3}$ : Financial target berpengaruh negatif pada financial statement fraud.

External pressure yaitu kondisi manajemen mengalami tekanan agar mampu mendapatkan pinjaman dari pihak eksternal dan mampu memenuhi kewajiban untuk membayar pinjaman tersebut. Untuk mendapatkan dana dari pihak eskternal perusahaan harus menampilkan performa rasio keuangan dan laba yang baik agar investor tertarik (Sulastri, 2019). Agency theory menjelaskan bahwa manajer bertanggungjawab atas pemegang saham, jika manajer tidak mampu mencari sumber pembiayaan tambahan maka akan kesulitan dalam 
mengelola perusahaan. Inilah yang menyebabkan tekanan bagi manajer, sehingga mendorong untuk melakukan tindakan financial statement fraud (Legowo, 2019). Penelitian yang dilakukan oleh Sihombing \& Rahardjo, (2014) mengatakan bahwa external pressure berpengaruh secara signfikan terhadap financial statement fraud. Penelitian tersebut sejalan dengan penelitian Septriyani \& Handayani, (2018) yang menjelaskan bahwa semakin tinggi nilai leverage ratio maka lebih besar kemungkinan terjadinya pelanggaran terhadap perjanjian kredit melalui tindakan kecurangan.

Nilai leverage ratio dijadikan proksi untuk variabel external pressure, apabila perusahaan memiliki nilai leverage ratio yang tinggi maka perusahaan tersebut memiliki pinjaman yang harus dibayarkan dalam jumlah besar dan menghadapi risiko kredit yang tinggi. Ketika perusahaan mampu mendapatkan pinjaman dari pihak eksternal menyebabkan manajemen harus melaporkan profitabilitas yang tinggi, sehingga tidak jarang perusahaan melakukan kecurangan pelaporan keuangan dengan cara menaikkan laba yang diperolehnya (Wahyuni \& Budiwitjaksono, 2017). Berdasarakan pemaparan external pressure yang diproksikan dengan leverage ratio (LEV) maka dapat disusun hipotesis empat yaitu, semakin tinggi nilai leverage ratio atau hutang yang dimiliki perusahaan, maka semakin tinggi kemungkinan terjadinya financial statement fraud.

$\mathrm{H}_{4}$ : External pressure berpengaruh positif pada financial statement fraud.

\section{METODE PENELITIAN}

Lokasi penelitian ini dilakukan pada perusahaan manufaktur yang terdaftar di Bursa Efek Indonesia (BEI) periode 2015-2019. BEI memberikan informasi laporan keuangan pada situs resminya di www.idx.co.id. Objek penelitian ini adalah financial statement fraud, financial stability, personal financial need, financial target dan external pressure. Populasi dalam penelitian ini adalah laporan keuangan perusahaan manufaktur yang terdaftar di Bursa Efek Indonesia selama periode 2015-2019. Jumlah populasi dalam penelitian ini yaitu 735 laporan keuangan perusahaan manufaktur yang terdaftar di Bursa Efek Indonesia selama periode 2015-2019. Pengujian parameter model dilakukan untuk mengetahui kelayakan model dan apakah koefisien yang diestimasi telah sesuai dengan teori atau hipotesis. Penelitian ini meliputi uji koefisien determinasi $\left(R^{2}\right)$, uji menyeluruh atau simultan (Uji F), dan uji individual atau parsial (Uji t). Secara matematis penelitian ini dapat digambarkan dalam fungsi sebagai berikut.

$$
Y=\alpha+\beta_{1} X_{1}+\beta_{2} X_{2}+\beta_{3} X_{3}+\beta_{4} X_{4}+\varepsilon
$$

Keterangan:

$\begin{array}{ll}\mathrm{Y} & =\text { Financial Statement Fraud } \\ \mathrm{a} & =\text { Konstanta } \\ \beta_{1}, \beta_{2}, \beta_{3}, \beta_{4} & =\text { Koefisien regresi masing-masing proksi } \\ \mathrm{X}_{1} & =\text { Financial Stability } \\ \mathrm{X}_{2} & =\text { Personal Financial Need } \\ \mathrm{X}_{3} & =\text { Financial Target } \\ \mathrm{X}_{4} & =\text { External Pressure } \\ \varepsilon & \end{array}$


Tabel 1. Ringkasan Pemilihan Sampel

\begin{tabular}{|c|c|c|}
\hline No & Keterangan & Tahun 2015-2019 \\
\hline 1 & $\begin{array}{l}\text { Perusahaan manufaktur yang terdaftar di Bursa Efek Indonesia } \\
\text { periode 2015-2019. }\end{array}$ & 147 \\
\hline 2 & $\begin{array}{l}\text { Perusahaan yang tidak mempublikasikan laporan keuangan } \\
\text { tahunan dalam website Bursa Efek Indonesia selama periode } \\
\text { 2015-2019. }\end{array}$ & (12) \\
\hline 3 & $\begin{array}{l}\text { Perusahaan yang mengalami kerugian, selama periode } 2015 \text { - } \\
2019 .\end{array}$ & (49) \\
\hline 4 & $\begin{array}{l}\text { Perusahaan yang tidak mengungkapkan data-data yang } \\
\text { berkaitan dengan variabel penelitian dan tersedia dengan } \\
\text { lengkap selama periode 2015-2019. }\end{array}$ & (62) \\
\hline 5 & $\begin{array}{l}\text { Perusahaan yang delisting dari Bursa Efek Indonesia selama } \\
\text { periode } 2015-2019 \text {. }\end{array}$ & (6) \\
\hline 6 & Data outliers & (6) \\
\hline & Jumlah perusahaan yang dijadikan sampel & 12 \\
\hline \multicolumn{2}{|r|}{ Jumlah sampel penelitian (12 perusahaan $\times 5$ tahun) } & 60 \\
\hline
\end{tabular}

Sumber: Data Penelitian, 2021

Pengambilan sampel menggunakan metode purposive sampling. Perhitungan sampel disajikan pada Tabel 1. Jumlah perusahaan yang memenuhi kriteria sebanyak 18 perusahaan dengan periode penelitian 5 tahun sehingga menghasilkan 90 data pengamatan. Namun, terdapat indikasi 6 data ekstrim sehingga jumlah unit analisis dalam penelitian adalah 60 data pengamatan. Data penelitian diperoleh dari laporan tahunan perusahaan yang dipublikasikan melalui website Bursa Efek Indonesia (www.idx.co.id).

\section{HASIL DAN PEMBAHASAN}

Uji regresi linier berganda dilakukan untuk mengetahui pengaruh dan signifikansi dari masing-masing variabel independen terhadap variabel dependen. Pengujian hipotesis terhadap koefisien regresi secara parsial dilakukan dengan membandingkan antara $t$ hitung dengan $t$ tabel, untuk menentukan nilai $t$ tabel ditentukan dengan tingkat signifikansi 5\%. Pengambilan keputusan adalah sebagai berikut.

Tabel 2. Hasil Uji Regresi Linier Berganda

\begin{tabular}{|c|c|c|c|c|c|}
\hline \multirow[t]{2}{*}{$\overline{\text { Model }}$} & \multicolumn{2}{|c|}{$\begin{array}{l}\text { Unstandardized } \\
\text { Coefficients }\end{array}$} & \multirow{2}{*}{$\begin{array}{c}\text { Standardized } \\
\text { Coefficients } \\
\text { Beta }\end{array}$} & \multirow[t]{2}{*}{$\mathrm{t}$} & \multirow[t]{2}{*}{ Sig. } \\
\hline & $B$ & Std. Error & & & \\
\hline (Constant) & $-0,017$ & 0,126 & &,- 136 & 892 \\
\hline Financial Stability & 0,496 & 0,255 & 0,237 & 1,940 & 0,018 \\
\hline $\begin{array}{l}\text { Personal } \\
\text { Financial Need }\end{array}$ & $-0,219$ & 0,158 & $-0,170$ & $-1,385$ & 0,172 \\
\hline Financial Target & $-0,933$ & 0,673 & 0,356 & 2,871 & 0,006 \\
\hline $\begin{array}{l}\text { External Pressure } \\
\text { R Square }=0,195 \\
\text { Nilai F }=3,323 \\
\text { F Sig }=0,017\end{array}$ & 0,350 & 0,272 & 0,161 & 1,286 & 0,204 \\
\hline
\end{tabular}

Sumber: Data Penelitian, 2021

Berdasarkan Tabel 2, dapat dilihat bahwa koefisien determinasi ( $R$ Square) yaitu 0,195. Artinya financial statement fraud (variabel dependen) dapat dijelaskan 
oleh financial stability, personal financial need, financial target dan external pressure (variabel independen) sebesar 19,5\%. Sisanya sebesar 80,5\% dijelaskan oleh variabel independen lain yang tidak diteliti pada penelitian ini.

Berdasarkan tabel 2 dapat dilihat bahwa nilai signifikansi sebesar 0,017 dimana lebih kecil dari 0,05 $(0,017<0,05)$. Sehingga dapat disimpulkan bahwa secara simultan variabel financial stability, personal financial need, financial target dan externalpressure berpengaruh signifikan pada financial statement fraud dan model regresi telah lulus uji kelayakan model. Berdasarkan Tabel 2, dapat dijelaskan bahwa persamaan regresinya sebagai berikut.

$$
\hat{\mathrm{Y}}=0,017+0,496 \mathrm{X} 1-0,219 \mathrm{X} 2+0,933 \mathrm{X} 3+0,350 \mathrm{X} 4
$$

Berdasarkan hasil pengujian uji-t diketahui bahwa variabel financial stability yang diproksikan dengan rasio pertumbuhan perubahan asset pertahun (ACHANGE) memiliki nilai koefisien sebesar 0,496 (positif) dan nilai signifikansi 0,018 lebih kecil dari 0,05, dengan demikian dapat disimpulkan bahwa variabel financial stability secara signifikan memberikan pengaruh positif terhadap financial statement fraud pada perusahaan manufaktur yang menjadi sampel dalam penelitian ini, maka $\mathrm{H}_{1}$ diterima.

Hal tersebut dapat terjadi karena kondisi pertumbuhan perubahan asset pertahun pada perusahaan manufaktur yang menjadi sampel dalam penelitian ini menunjukan kondisi yang tidak stabil. Tidak stabilnya kondisi keuangan perusahaan menjadi tekanan bagi manajer dalam mencapai kepentingan pemegang saham, yang dapat memicu manajer untuk melakukan financial statement fraud guna menunjukan keadaaan yang stabil. Sehingga dapat disimpulkan bahwa apabila kondisi keuangan perusahaan tidak stabil, maka terjadinya financial statement fraud akan meningkat.

Hasil penelitian ini mendukung penelitian sebelumnya yang dilakukan oleh Alfina \& Amrizal, (2020), Rahma \& Suryani, (2019) yang menyatakan bahwa tekanan yang diukur dengan perubahan total aset berpengaruh positif terhadap financial statement fraud. Namun penelitian ini bertentangan dengan penelitian Kayoi \& Fuad, (2019).

Kondisi ini sesuai dengan agency theory yang menyatakan bahwa manajer bertanggungjawab kepada pemegang saham, ketika perusahaan dalam keadaan tidak stabil maka pemegang saham akan menilai kinerja manajer buruk sehingga kondisi ini mendorong manajer untuk melakukan financial statement fraud agar kondisi perusahaan selalu terlihat stabil (Zelin, 2018).

Hasil pengujian uji-t menunjukan bahwa variabel personal financial need yang diukur dengan rasio antara jumlah saham yang dimiliki pihak manajerial (manajer dan direksi) terhadap total saham yang beredar memiliki nilai koefisien sebesar 0,219 (negatif) dan nilai signifikan sebesar 0,172 lebih besar dari 0,05. Dengan demikian dapat disimpulkan bahwa varibel personal financial need tidak berpengaruh secara signifikan terhadap financial statement fraud pada perusahaan manufaktur yang menjadi sampel dalam penelitian ini, sehingga $\mathrm{H}_{2}$ ditolak.

Hal tersebut dapat terjadi karena rendahnya rata-rata kepemilikan saham oleh manajer, direksi maupun komisaris pada perusahaan manufaktur yang menjadi sampel dalam penelitian ini. Kepemilikan saham dapat dikatakan rendah bila berkisar dari $0 \%$ sampai dengan 30\%, hasil dari kepemilikan saham pada perusahaan manufaktur yang menjadi sampel dalam penelitian ini tergolong 
rendah. Hal tersebut menunjukan adanya pemisahan wewenang yang baik antara tugas pemegang saham sebagai pengawas jalannya perusahaan dan manajer sebagai pengelola perusahaan. Pemisahan ini menyebabkan manajer cenderung akan berhati-hati dalam melakukan sesuatu yang berhubungan dengan perusahaan dan juga berhati- hati dalam pengambilan keputusan. Manajer akan berhati-hati disebabkan karena setiap tindakan atau keputusan yang diambil oleh manajer akan berdampak pada kesejahteraan dirinya sendiri sebagai pemegang saham perusahaan. Sehingga apabila manajer melakukan kecurangan maka akan merugikan dirinya sendiri (Chandra \& Suhartono, 2020).

Hasil penelitian ini sejalan dengan penelitian yang dilakukan oleh Setiawati \& Baningrum, (2018), Chandra \& Suhartono, (2020) yang menyatakan bahwa personal financial needs tidak terbukti berpengaruh terhadap kemungkinan terjadinya fraudulent financial reporting. Namun penelitian ini bertolak belakang dengan hasil penelitian yang dilakukan oleh Utomo, (2018).

Berdasarkan hasil pengujian uji-t diketahui bahwa variabel financial target yang diukur menggunakan rasio profitabilitas yaitu Return on Asset (ROA) memiliki nilai koefisien sebesar -0,933 (negatif) dan nilai signifikan sebesar 0,006 lebih kecil dari 0,05. Dengan demikian dapat disimpulkan bahwa variabel financial target berpengaruh negatif terhadap financial statement fraud pada perusahaan manufaktur yang menjadi sampel pada penelitian ini, maka $\mathrm{H}_{3}$ diterima.

Hasil ini menunjukan bahwa meningkatnya ROA atau kenaikan profitabilitas pada perusahaan manufaktur yang menjadi sampel dalam penelitian ini, diakibatkan pada peningkatan mutu operasional perusahaan pemilihan sumber daya yang berkualitas, penerapan kebijakan yang mampu meningkatkan nilai perusahaan seperti manajemen pemasaran guna meningkatkan penjualan, pemilihan metode penyusutan yang tepat sehingga beban penyusutan lebih rendah sehingga dapat meningkatkan laba (Haryono, 2017).

Hasil penelitian ini mendukung penelitian yang dilakukan oleh Sulastri, (2019) dan Dewi, (2020) yang membuktikan bahwa financial target berpengaruh negatif terhadap financial statement fraud. Namun penelitian ini bertentangan dengan hasil penelitian yang dilakukan Jao, et al., (2021).

Keadaan ini sesuai dengan agency theory yang menyatakan bahwa adanya hubungan kerjasama antara manajer dengan pemegang saham, dimana pemegang saham memberikan target profitabilitas dan manajer telah bertanggungjawab dengan melakukan peningkatan mutu operasional perusahaan untuk mencapai target tersebut.

Hasil pengujian uji-t menunjukan bahwa variabel externalpressure yang diukur menggunakan leverage ratio (LEV) memiliki nilai koefisien sebesar 0,350 (positif) dan nilai signifikan sebesar 0,204 lebih besar dari 0,05. Dengan demikian dapat disimpulkan bahwa variabel external pressure tidak berpengaruh secara signifikan terhadap financial statement fraud pada perusahaan manufaktur yang menjadi sampel pada penelitian ini, maka H4 ditolak.

Kemungkinan hal ini dapat terjadi karena tingginya leverage ratio bukan menjadi tekanan bagi pihak manajemen untuk melakukan financial statement fraud. Manajemen memperoleh sumber pembiayaan tidak hanya melalui perjanjian hutang dengan kreditor, namun bisa diperoleh dengan melakukan penerbitan saham kembali agar memperoleh sumber modal dari pihak investor. Dengan 
demikian dapat mengurangi tekanan dalam hal membayar hutang, dan mencegah tekanan yang dapat menimbulkan manajemen untuk melakukan financial statement fraud (Ijudien, 2018).

Hasil penelitian ini mendukung penelitian yang dilakukan oleh Ratnasari \& Solikhah, (2019) yang menyatakan secara empiris tekanan eksternal tidak berpengaruh terhadap kecurangan laporan keuangan. Namun penelitian ini bertolak belakang dengan hasil penelitian Putriasih, et al., (2016).

Hasil penelitian ini memberikan pandangan bahwa tekanan yang berlebihan bagi manajer untuk memenuhi apa yang diinginkan pemegang saham sesuai dengan hubungan dalam agency theory tidak berarti manajer menambah hutang yang akan menimbulkan beban tinggi yang dapat mendorong manajer melakukan financial statement fraud.

Hasil penelitian ini memberikan sebuah implikasi kepada investor yang akan melakukan investasi disuatu perusahaan dapat melihat terlebih dahulu rasio pertumbuhan perubahan asset pertahun pada laporan keuangan perusahaan sebelum melakukan investasi, karena berdasarkan hasil penelitian ini apabila kondisi pertumbuhan perubahan asset pertahun pada perusahaan tidak stabil maka dapat memicu manajer untuk melakukan financial statement fraud. Dengan memperhatikan kondisi pertumbuhan perubahan asset pertahun pada perusahaan dapat mengurangi potensi investor mengalami kerugian dalam berinvestasi akibat dari adanya kecurangan laporan keuangan.

\section{SIMPULAN}

Variabel financial stability yang diproksikan dengan rasio pertumbuhan perubahan asset pertahun berpengaruh positif dan signifikan terhadap financial statementfraud pada perusahaan manufaktur yang menjadi sampel dalam penelitian ini. Semakin tinggi rasio perubahan total aset suatu perusahaan maka semakin tinggi juga tingkat risiko terjadinya financial statement fraud. Variabel personal financial need yang diukur dengan rasio antara jumlah saham yang dimiliki pihak manajerial (manajer dan direksi) terhadap total saham yang beredar, tidak memiliki pengaruh terhadap financial statement fraud pada perusahaan manufaktur yang menjadi sampel dalam penelitian ini. Variabel financial target yang diukur menggunakan rasio profitabilitas berpengaruh negatif dan signifikan terhadap financial statement fraud pada perusahaan manufaktur yang menjadi sampel dalam penelitian ini. Semakin meningkatnya financial target yang ditetapkan perusahaan, semakin rendah kemungkinan terjadinya financial statement fraud. Variabel external pressure yang diukur menggunakan leverage ratio tidak memiliki pengaruh terhadap financial statement fraud pada perusahaan manufaktur yang menjadi sampel dalam penelitian ini.

Diharapkan perusahaan dapat menerapakan pemisahan wewenang yang baik antara tugas pemegang saham sebagai pengawas jalannya perusahaan dan manajer sebagai pengelola perusahaan, karena hal tersebut dapat mengurangi potensi terjadinya financial statement fraud (Chandra \& Suhartono, 2020). Berdasarkan hasil penelitian ini personal financial need tidak berpengaruh terhadap financial statement fraud. Diharapkan menajer perusahaan dapat mencari cara lain untuk memperoleh sumber pembiayaan, seperti melakukan penerbitan saham kembali agar memperoleh sumber modal dari pihak investor, sehingga 
mengurangi tekanan yang dapat menimbulkan potensi terjadinya financial statement fraud, karena berdasarkan hasil penelitian ini external pressure yang diukur menggunakan leverage ratio tidak memiliki pengaruh terhadap financial statement fraud.

\section{REFERENSI}

Akbar, T. (2017). The Determination of Fraudulent Financial Reporting Causes by Using Pentagon Theory on Manufacturing Companies in Indonesia. International Journal of Business, Economics and Law, 14(5), 106-113.

Alfina, D. F., \& Amrizal, A. (2020). Pengaruh Faktor Tekanan, Peluang, Rasionalisasi, Kompetensi, dan Arogansi Terhadap Kecurangan Laporan Keuangan. Akuntabilitas: Jurnal Ilmu Akuntansi, 13(1), 63-76. https://doi.org/10.15408/akt.v13i1.14497

Annisya, M., Lindrianasari, \& Asmaranti, Y. (2016). Pendeteksian Kecurangan Laporan Keuangan Menggunakan Fraud Diamond. Jurnal Bisnis Dan Ekonomi (JBE), 23(1), 72-89.

Bawekes, H. F., Simanjuntak, A. M., \& Christina Daat, S. (2018). Pengujian Teori Fraud Pentagon terhadap Fraudulent Financial Resporting (Studi Empiris pada Perusahaan yang Terdaftar di Bursa Efek Indonesia Tahun 2011-2015). Jurnal Akuntansi \& Keuangan Daerah, 13(1), 114-134.

Chandra, N., \& Suhartono, S. (2020). Analisis Pengaruh Fraud Diamond Dan Good Corporate Governance Dalam Mendeteksi Kemungkinan Terjadinya Fraudulent Financial Statement. Jurnal Bina Akuntansi, 7(2), 175-207. https://doi.org/10.52859/jba.v7i2.93

Darmawan, A., \& Saragih, S. O. (2017). The Impact of Auditor Quality, Financial Stability, and Financial Target for Fraudulent Financial Statement. Journal of Applied Accounting and Taxation, 2(1), 9-14. https://jurnal.polibatam.ac.id/index.php/JAAT/article/view/542

Dechow, P. M., Ge, W., Larson, C. R., \& Sloan, R. G. (2011). Predicting Material Accounting Misstatements. Contemporary Accounting Research, 28(1), 17-82. https://doi.org/10.1111/j.1911-3846.2010.01041.x

Dewi, F. R. (2020). Dimensi Fraud Pentagon terhadap Kecurangan Laporan Keuangan pada Perusahaan Perbankan yang Terdaftar di Bursa Efek Indonesia Periode 2015-2018. Skripsi. Universitas Pancasakti Tegal.

Haryono, M. (2017). Analisis Fraud Triangle Dalam Mendeteksi Financial Statement Fraud. Tesis. Sarjana Ekonomi Fakultas Ekonomi dan Bisnis Universitas Muhammadiyah Surakarta.

Husmawati, P., Septiarini, Y., Rosita, I., \& Handayani, D. (2017). Fraud Pentagon Analysis in Assessing the Likelihood of Fraudulent Financial Statement (Study on Manufacturing Firms Listed in Bursa Efek Indonesia Period 20132016). International Conference of Applied Science on Engineering, Business, Linguistics and Information Technology, 45-51.

Ijudien, D. (2018). Pengaruh Stabilitas Keuangan, Kondisi Industri dan Tekanan Eksternal terhadap Kecurangan Laporan Keuangan. Jurnal Kajian Akuntansi, 2(1), 82-97.

Indarto, S. L., \& Ghozali, I. (2016). Fraud diamond: Detection analysis on the fraudulent financial reporting. Risk Governance and Control: Financial Markets 
and Institutions, 6(4), 116-123. https://doi.org/10.22495/rcgv6i4c1art1

Iqbal, M., \& Murtanto. (2016). Analisa Pengaruh Faktor-Faktor Fraud Triangle terhadap Kecurangan Laporan Keuangan pada Perusahaan Property dan Real Estate yang Terdaftar di Bursa Efek Indonesia. Seminar Nasional Cendekiawan 2016, ISSN: 2540-7589, 17, 1-20.

Jao, R., Mardiana, A., Holly, A., \& Chandra, E. (2021). Pengaruh Financial Target dan Financial Stability terhadap Financial Statement Fraud. Journal Of Management, 4(1), 27-42. https://doi.org/10.37531/yum.v11.76

Kayoi, S. A., \& Fuad. (2019). Faktor-Faktor Yang Mempengaruhi Financial Statement Fraud Ditinjau Dari Fraud Triangle Pada Perusahaan Manufaktur Di Bursa Efek Indonesia Periode 2015-2017. Diponegoro Journal of Accounting, $8(4), 1-13$.

Legowo, I. S. (2019). Pengaruh Faktor-Faktor Fraud Pentagon dan Keahlian Komite Audit terhadap Fraudulent Financial Reporting. Skripsi. Universitas Pancasakti Tegal.

Maghfiroh, N., Ardiyani, K., \& Syafnita. (2015). Analisis Pengaruh Financial Stability, Personal Financial Need, External Pressure, dan Ineffective Monitoring pada Financial Statement Fraud dalam Perspektif Fraud. Jurnal Ekonomi Dan Bisnis, 16(1), 51-66.

Mardianto, M., \& Tiono, C. (2019). Analisis Pengaruh Fraud Triangle Dalam Mendeteksi Kecurangan Laporan Keuangan. Jurnal Benefita, 4(1), 87-103. https://doi.org/10.22216/jbe.v1i1.3349

Nurrizkiana, R. (2015). Analisis Fraud Triangle dalam Mendeteksi Financial Statement Fraud. Jurnal Akuntansi Universitas Pendidikan Indonesia.

Prasmaulida, S. (2016). Financial Statement Fraud Detection Using Perspective of Fraud Triangle Adopted By Sas No. 99. Asia Pacific Fraud Journal, 1(2), 317335. https://doi.org/10.21532/apfj.001.16.01.02.24

Pratiya, M. A. M., \& Susetyo, B. (2018). Pengaruh Stabilitas Keuangan, Target Keuangan Tingkat Kinerja, Rasio Perputaran Aset, Keahlian Keuangan Komite Audit, dan Profitabilitas Terhadap Fraudulent Financial Statement. Permana: Jurnal Perpajakan, Manajemen, Dan Akuntansi, 10(1), 116-131. https://doi.org/10.24905/ permana.v10i2.86

Pusphita, M. Y., \& Yassa, G. W. (2018). Fraud Pentagon Analysis in Detecting Fraudulent Financial Reporting (Study on Indonesian Capital Market). International Journal of Sciences: Basic and Applied Research, 42(5), 93-109.

Putriasih, K., Herawati, N. N. T., \& Wahyuni, M. A. (2016). Analisis Fraud Diamond Dalam Mendeteksi Financial Statement Fraud: Studi Empiris Pada Perusahaan Manufaktur Yang Terdaftar Di Bursa Efek Indonesia (BEI) Tahun 2016 - 2018. E-Journal S1 Ak Universitas Pendidikan Ganesha, 6(3). https://doi.org/10.25105/ semnas.v0i0.5780

Rachmania, A. (2017). Analisis Pengaruh Fraud Triangle terhadap Kecurangan Laporan Keuangan Pada Perusahaan Makanan dan Minuman Yang Terdaftar Di Bursa Efek Indonesia Periode 2013-2015. Jurnal Online Mahasiswa, 2(2), 119.

Rahma, D. V., \& Suryani, E. (2019). Pengaruh Faktor-Faktor Fraud Triangle Terhadap Financial Statement Fraud. Jurnal ASET (Akuntansi Riset), 11(2), 301-314. https://doi.org/10.17509/jaset.v11i2.17926 
Ratnasari, E., \& Solikhah, B. (2019). Analysis of Fraudulent Financial Statement: The Fraud Pentagon Theory Approach Analisis Kecurangan Laporan Keuangan: Pendekatan Fraud Pentagon Theory. Gorontalo Accounting Journal, 2(2), 98-112.

Riandani, M. A., \& Rahmawati, E. (2019). Pengaruh Fraud Pentagon, Kepemilikan Institusional dan Asimetris Informasi Terhadap Kecurangan Laporan Keuangan (Studi Empiris pada Perusahaan Perbankan yang Terdaftar Di Bursa Efek Indonesia Tahun 2015-2017). Reviu Akuntansi Dan Bisnis Indonesia, 3(2), 179-189. https://doi.org/10.18196/rab.030244

Saputra, M. A. R., \& Kusumaningrum, N. D. (2017). Analisis Faktor-Faktor yang Mempengaruhi Fraudulent Financial Reporting dengan Perspektif Fraud Pentagon pada Perusahaan Perbankan yang Terdaftar di Bursa Efek Indonesia tahun 2011-2015. Jurnal Akuntansi Dan Keuangan, 22(2), 107-120.

Septriyani, Y., \& Handayani, D. (2018). Mendeteksi Kecurangan Laporan Keuangan dengan Analisis Fraud Pentagon. Jurnal Akuntansi, Keuangan Dan Bisnis, 11(1), 11-23. http://jurnal.pcr.ac.id

Setiawati, E., \& Baningrum, R. M. (2018). Deteksi Fraudulent Financial Reporting Menggunakan Analisis Fraud Pentagon: Studi Kasus Pada Perusahaan Manufaktur Yang Listed Di BEI Tahun 2014-2016. Riset Akuntansi Dan Keuangan Indonesia, 3(2), 91-106.

Siddiq, R., Achyani, F., \& Zulfikar. (2017). Fraud Pentagon Dalam Mendeteksi Financial Statement. Seminar Nasional Dan the 4Th Call Syariah Paper, (ISSN 2460-0784), 1-14. http://hdl.handle.net/11617/9210

Sihombing, K. S., \& Rahardjo, S. N. (2014). Analisis Fraud Diamond Dalam Mendeteksi Financial Statement Fraud: Studi Empiris Pada Perusahaan Manufaktur Yang Terdaftar Di Bursa Efek Indonesia (Bei) Tahun 2016 - 2018. Diponegoro Journal of Accounting, 03(02), 1-12. https://doi.org/10.25105/ semnas.v0i0.5780

Skousen, C. J., Smith, K. R., \& Wright, C. J. (2011). Detecting and Predicting Financial Statement Fraud: The Effectiveness of the Fraud Triangle and SAS No. 99. SSRN Electronic Journal, 1-39. https:/ / doi.org/10.2139/ssrn.1295494

Sukrisnadi, D. (2010). Pemakaian Ukuran F-Score dalam Kasus-Kasus Salah Saji Laporan Keuangan di Pasar Modal Indonesia. Tesis. Fakultas Ekonomi dan Bisnis Universitas Indonesia.

Sulastri, N. (2019). Analisis Fraud Triangle dan Ukuran Perusahaan dalam Mendeteksi Potensi Kecurangan Laporan Keuangan. Skripsi. Universitas Islam Indonesia.

Tiffani, L., \& Marfuah. (2015). Deteksi Financial Statement Fraud dengan Analisis Fraud Triangel pada Perusahaan Manufaktur yang Terdaftar Di Bursa Efek Indonesia. Jurnal Akuntansi Dan Auditing Indonesia, 19(2), 112-125.

Utomo, L. P. (2018). Kecurangan Dalam Laporan Keuangan "Menguji Teori Fraud Triangle." Jurnal Akuntansi Dan Pajak, 19(1), 77-88. https://doi.org/10.29040/jap.v19i1.241

Wahyuni, W., \& Budiwitjaksono, G. S. (2017). Fraud Triangle sebagai Pendeteksi Kecurangan Laporan Keuangan. Jurnal Akuntansi, 21(1), 47-61. https://doi.org/10.24912/ja.v21i1.133

Yesiariani, M., \& Rahayu, I. (2016). Analisis Fraud Diamond Dalam Mendeteksi ( 
Studi Empiris pada Perusahaan LQ-45 yang Terdaftar di Bursa Efek Indonesia Tahun 2010 - 2014 ). Simposium Nasional Akuntansi XIX, Lampung, $1-22$.

Zaki, N. M. (2017). The Approriateness of Fraud Triangle and Diamond Models in Assessing The Likelihood of Fraudulent Financial Statements-An Empirical Study on Firms Listed in The Egyptian Stock Exchange. International Journal of Social Science and Economic Research, 02(02), 2403-2433.

Zelin, C. (2018). Analisis Fraud Pentagon dalam Mendeteksi Kecurangan Laporan Keuangan dengan Menggunakan Fraud Score Model. Skripsi. Universitas Islam Indonesia. 